\title{
Papillary Cannulation Facilitated by Submucosal Saline Injection into an Intradiverticular Papilla
}

\author{
Kanglock Lee ${ }^{1}$, Ji Wook Choi ${ }^{1}$, Yunhyeong Lee ${ }^{1}$, Joung-Ho Han ${ }^{1,2}$ and Seon Mee Park ${ }^{1,2}$ \\ Department of Internal Medicine, ${ }^{1}$ Chungbuk National University Hospital, Cheongju, ${ }^{2}$ Chungbuk National University College of Medicine, \\ Cheongju, Korea
}

Endoscopic retrograde cholangiopancreatography (ERCP) of the intradiverticular papilla with its invisible orifice remains challenging. Several techniques have been introduced to evert the papillary opening to facilitate cannulation. A 79-year-old woman with bile duct stones underwent ERCP, which revealed that the papilla was located inside a large diverticulum and tended to rotate inward with a trial of papillary cannulation. Submucosal papillary injection of $3 \mathrm{cc}$ of normal saline was performed at 3 and 9 o'clock. Eversion and fixation of a papilla in the diverticulum with this technique allowed selective cannulation of the biliary tree. Stones were retrieved after endoscopic papillary balloon dilation without complications. She had an uneventful post-procedural course. Our findings suggest that submucosal saline injection technique is safe and effective for selective cannulation and can be recommended when cannulation is very difficult because of an intradiverticular papilla. Clin Endosc 2019;52:83-86

Key Words: Cholangiopancreatography, endoscopic retrograde; Gallstones; Ampulla of Vater; Intradiverticular papilla; Submucosal injection

\section{INTRODUCTION}

Periampullary diverticula (PAD) are present in $7.5 \%-20 \%$ of all endoscopic retrograde cholangiopancreatography (ERCP) cases $^{1,2}$ and are classified by the position of the major papilla as inside, marginal to, or near the duodenal diverticulum within a $2-\mathrm{cm}$ radius. ${ }^{3}$ Recent studies reported that the technical success or complication rates of ERCP did not increase in patients with PAD. ${ }^{4}$ However, ERCP through an intradiverticular papilla, especially one with an invisible orifice, remains difficult, and success rates are lower with an invisible orifice. ${ }^{5}$ Several techniques have been introduced to evert the

Received: March 20, 2018 Revised: May 2, 2018

Accepted: May 3, 2018

Correspondence: Seon Mee Park

Department of Internal Medicine, Chungbuk National University College of Medicine, 1 Chungdae-ro, Seowon-gu, Cheongju 28644, Korea

Tel: +82-43-269-6019, Fax: +82-43-273-3252, E-mail: smpark@chungbuk.ac.kr

ORCID: https://orcid.org/0000-0002-5835-2741

(c) This is an Open Access article distributed under the terms of the Creative Commons Attribution Non-Commercial License (http://creativecommons.org/ licenses/by-nc/3.0) which permits unrestricted non-commercial use, distribution, and reproduction in any medium, provided the original work is properly cited. papillary opening to facilitate cannulation. ${ }^{1,6-15}$ Submucosal injection, ${ }^{6}$ endoscopic clipping, ${ }^{9}$ and two-devices-in-one-channel, ${ }^{10}$ have been introduced. The submucosal injection method involves lifting of the mucosa to enable eversion and fixing of a papilla in the diverticulum and allows selective cannulation of the biliary tree. ${ }^{6}$ This may be a safe and convenient technique and is easily performed in ordinary ERCP settings.

We report a case of cholelithiasis with an intradiverticular papilla treated using the submucosal saline injection method, and also provide a literature review.

\section{CASE REPORT}

A-79-year-old-woman was admitted to our hospital with a 1-week history of epigastric pain but no fever or jaundice. Physical examination on admission revealed mild epigastric tenderness. Laboratory data showed a white blood cell count of $6,120 / \mathrm{mm}^{3}$, hemoglobin of $11.0 \mathrm{~g} / \mathrm{dL}$, hematocrit of $33.9 \%$, platelet count of $189 \times 10^{3} / \mathrm{mm}^{3}$, total protein of $6.8 \mathrm{~g} / \mathrm{dL}$, albu$\min$ of $4.3 \mathrm{~g} / \mathrm{dL}$, aspartate aminotransferase of $32 \mathrm{U} / \mathrm{L}$, alanine 
aminotransferase of $33 \mathrm{U} / \mathrm{L}$, alkaline phosphatase of $34 \mathrm{U} / \mathrm{L}$, total bilirubin of $0.39 \mathrm{mg} / \mathrm{dL}$, amylase of $25 \mathrm{U} / \mathrm{L}$, and lipase of $27 \mathrm{U} / \mathrm{L}$. Abdominal computed tomography revealed a round stone in the dilated common bile duct and presence of a periampullary diverticulum (Fig. 1). ERCP revealed that the papilla was at the inferior border of a large duodenal diverticulum (Fig. 2A), and the papilla could not be cannulated with a usual method because of inward rotation. We tried cannulation by entering the duodenal diverticulum, ${ }^{14}$ and a double-catheter method, ${ }^{15}$ but failed. We chose the submucosal saline injection method to enable eversion and fixation of the papilla in the diverticulum. The submucosal injection of $3 \mathrm{cc}$ of saline at 3 and 9 oclock on the papilla enabled eversion and fixation in the diverticulum and the ability to performed selective cannulation of the biliary tree (Fig. 2B). After endoscopic papillary balloon dilation (EPBD, $10 \mathrm{~mm}$ for $60 \mathrm{~s}$ ), the stones were extracted (Fig. 1C) and a Zimmon single pigtailed biliary stent (7 F, $5 \mathrm{~cm}$ ) (Cook Medical, Bloomington, IN, USA) was placed. The patient had an uneventful post-procedural course and has been asymptomatic for 2 years.

\section{DISCUSSION}

ERCP in patients with PAD is not difficult when performed by experienced endoscopists using specialized techniques and devices. ${ }^{7.8}$ Endoscopists must be aware of available cannulation techniques in specific conditions of the papilla. Several techniques have been introduced to facilitate cannulation in the setting of intradiverticular papilla (Table 1). ${ }^{1,69-18}$ To enable informed decisions and ensure the best outcomes, endoscopists should be aware of differences in technical feasibility and safety of each technique. The best method depends on the endoscopist's preference and patient conditions. The main goal of various techniques involves bringing the papilla into a better orientation by grasping, pushing, or lifting, or by performing pancreatic duct stenting. ${ }^{7}$ Several different methods, such as submucosal injection, ${ }^{6}$ endoscopic clipping, ${ }^{9}$ two-devices-in-one-channel, ${ }^{10}$ reverse guidewire anchoring, ${ }^{11}$ double endoscopy, ${ }^{12}$ cap-assisted with forward viewing endoscopy, ${ }^{13}$ entering the duodenal diverticulum with the distal tip of the duodenoscope, ${ }^{14}$ and pre-cut biliary sphincterotomy after pancreatic duct stent placement ${ }^{1}$ have been introduced.
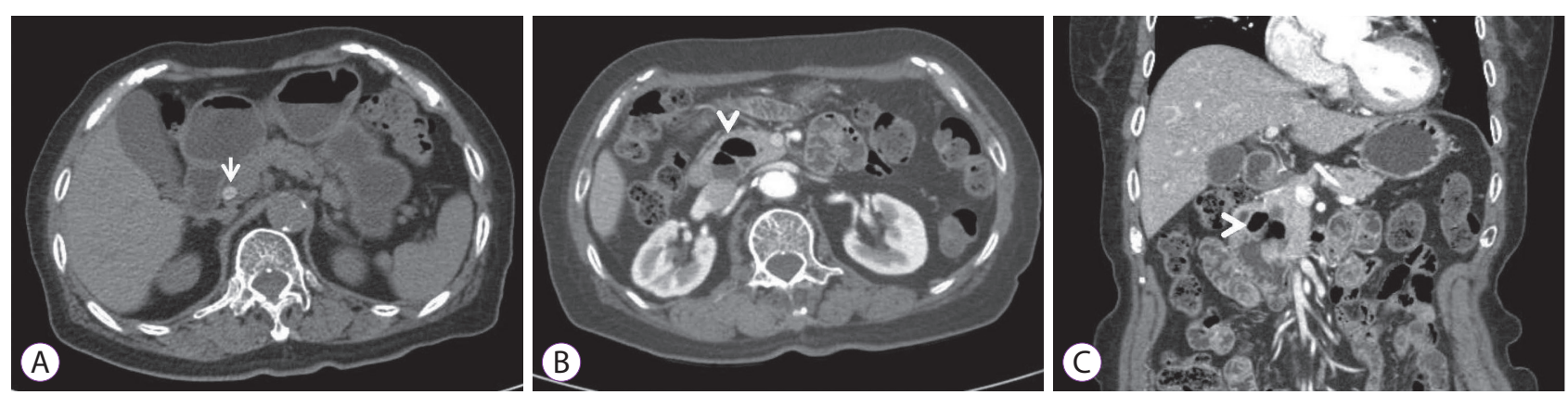

Fig. 1. Abdominal computed tomography. (A) Pre-contrast axial scan showed a hyperdense lesion inside the dilated common bile duct. (B, C) Post-contrast axial scan and coronal view revealed the presence of a periampullary diverticulum (arrowheads).
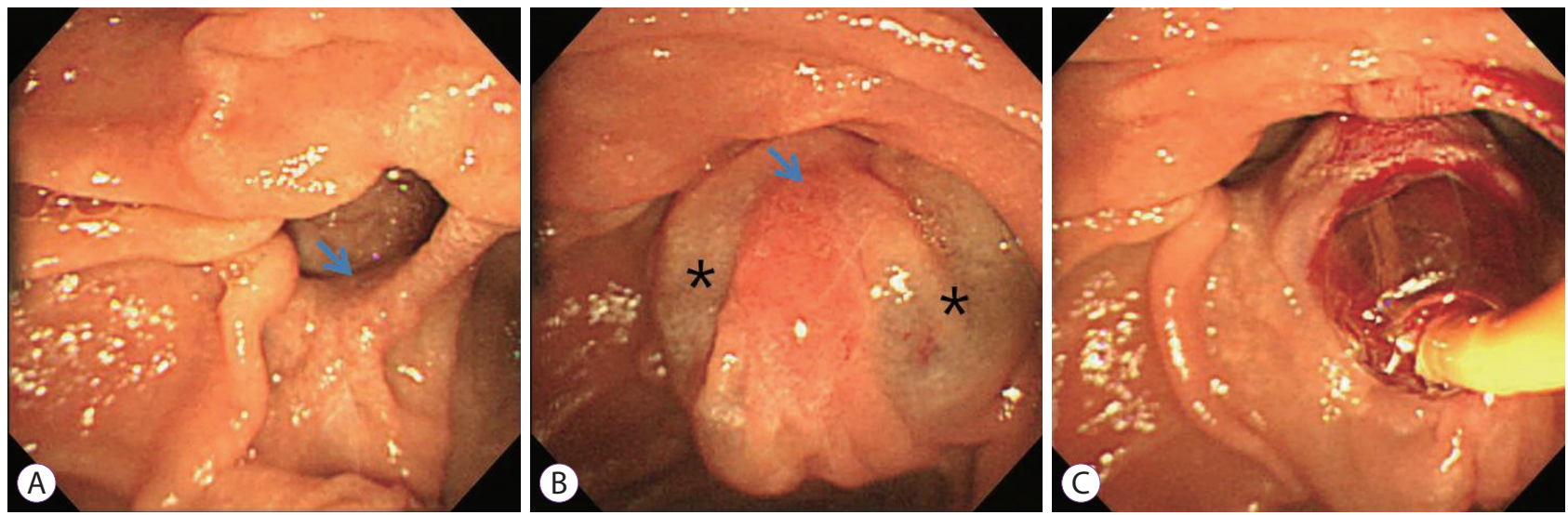

Fig. 2. Duodenoscopic findings during endoscopic retrograde cholangiopancreatography. (A) The major duodenal papilla (arrow) is positioned inside the diverticulum. (B) Saline injection was performed at 3 and 9 o'clock (stars) for eversion and fixation of the papilla (arrow). (C) Endoscopic papillary balloon dilation preceded stone extraction. 
Table 1. Techniques for Difficult Cannulation in Periampullary Diverticulum

\begin{tabular}{|c|c|c|}
\hline Techniques & Scopes & Devices \\
\hline $\begin{array}{l}\text { Pancreatic duct stent placement followed by pre-cut biliary } \\
\text { sphincterotomy }{ }^{1}\end{array}$ & Duodenoscope & Pancreatic duct stent, pre-cut needle knife \\
\hline Submucosal saline injection ${ }^{6}$ & Duodenoscope & Saline injector \\
\hline Endoclip-assisted cannulation ${ }^{9}$ & Duodenoscope & One or more endoclips \\
\hline Two-devices in one-channel method ${ }^{10,15}$ & Duodenoscope & Biopsy forceps, catheter \\
\hline Reversed guidewire method ${ }^{11}$ & Duodenoscope & Reversed guidewire (stiff end forward) \\
\hline Double endoscope method ${ }^{12}$ & Duodenoscope, Gastroscope & Foreign body forceps \\
\hline Cap-assisted cannulation ${ }^{13}$ & Gastroscope & Transparent cap, needle papillotome \\
\hline Entering the duodenal diverticulum ${ }^{14}$ & Duodenoscope & None \\
\hline Balloon dilation of the narrow diverticular neck ${ }^{16}$ & Duodenoscope & Stone retrieval balloon \\
\hline Percutaneous ultrasound-guided rendezvous technique ${ }^{17}$ & Duodenoscope & Abdominal ultrasound \\
\hline EUS-guided rendezvous technique ${ }^{18}$ & Duodenoscope & Endoscopic ultrasound \\
\hline
\end{tabular}

EUS, endoscopic ultrasonography.

Endoscopic clips are used to evert and stabilize the papillary opening. ${ }^{9}$ Deployment of endoscopic clips at the proper positions could be improved using rotatable devices. The twodevices-through-one-channel method exposes the papilla using different devices: grasping by biopsy forceps ${ }^{10}$ or pushing by a catheter ${ }^{15}$ or reverse guidewire. ${ }^{11}$ The reverse guidewire method involves pushing the adjacent mucosa of the papilla toward the duodenal lumen and straightening the folds using the stiff reverse end of the guidewire. ${ }^{11}$ Because the two devices work in the same direction, coordination of the two instruments is sometimes difficult. The double endoscope method involves grasping the tissue just beside the papilla with foreign body forceps through the attached clear gastroscope cap and insertion of the duodenoscope alongside the gastroscope for cannulation. ${ }^{12}$ Direct visualization of the papillary orifice using cap-assisted forward viewing endoscopy ${ }^{13}$ or entering the duodenal diverticulum with the distal tip of the duodenoscope $^{14}$ can be effective in some conditions. If the pancreatic duct is cannulated, stent placement aims to keep the papilla out of the diverticulum, and a pre-cut biliary sphincterotomy is performed, which can be helpful for selective biliary cannulation. ${ }^{1}$ For patients with a narrow-necked diverticulum, balloon dilation inside the diverticulum allows papillary eversion. $^{16}$

When ERCP fails, alternative methods, such as percutaneous ultrasound-guided ${ }^{17}$ or endoscopic ultrasound-guided ${ }^{18}$ rendezvous technique can be attempted. After percutaneous ultrasound-guided transhepatic biliary puncture or endoscopic ultrasound-guided bile duct puncture, a guidewire is inserted into the bile duct and across the papilla under fluoroscopic guidance to enable deep bile duct cannulation.

Here we used the submucosal saline injection method to lift the papilla into the diverticulum. The submucosal injection of 2-4 mL of normal saline at single or multiple points enables intradiverticular papillary eversion. The important step is selecting the best inflation point to preserve the bile duct opening and to maintain papillary eversion. To prolong the submucosal indwelling time, a hyperviscous fluid, such as sodium hyaluronate, can be used. Harada et al. used sodium hyaluronate as an injection fluid for lifting of an intradiverticular papilla and successfully performed ERCP in five cases. ${ }^{6}$ They performed endoscopic sphincterotomy (EST) and pancreatic stent placement to prevent post-ERCP pancreatitis. We preferred normal saline as the lifting material because papillary cannulation can be performed within several minutes before normal saline absorption. The absorption of normal saline within several minutes may have an advantage of preventing pancreatitis. We did not perform any procedure to prevent pancreatitis. This method is safe as well as convenient as it requires neither endoscopy changes nor specialized equipment. The injection needle is easily available in ordinary ERCP rooms.

We performed EPBD because of an undefined upper margin due to the saline injection and retrieved bile duct stones. When a large EST is technically difficult in patients with a PAD, EPBD alone or EPBD combined with small EST are alternatives. $^{19}$

For patients with PAD, papillary identification is sometimes difficult. Papillae are usually located on the lower margin of or just inside the diverticulum, somewhere between the 4 and 8 oclock positions. ${ }^{7}$ Cannulation is more difficult when a papilla is positioned at the 1 oclock position in the diverticulum. ${ }^{2}$ In the present case, the papilla was located at the 5 oclock position, and so it could be easily detected. One study reported 
that an ultrathin gastroscope was used to locate a papilla hidden within a duodenal diverticulum. ${ }^{20}$

In conclusion, the submucosal saline injection method may be a safe and convenient technique for biliary cannulation and may be recommended when selective cannulation is difficult in patients with an intradiverticular papilla.

\section{Conflicts of Interest}

The authors have no financial conflicts of interest.

\section{REFERENCES}

1. Fogel EL, Sherman S, Lehman GA. Increased selective biliary cannulation rates in the setting of periampullary diverticula: main pancreatic duct stent placement followed by pre-cut biliary sphincterotomy. Gastrointest Endosc 1998;47:396-400.

2. Parlak E, Suna N, Kuzu UB, et al. Diverticulum with papillae: does position of papilla affect technical success? Surg Laparosc Endosc Percutan Tech 2015;25:395-398.

3. Boix J, Lorenzo-Zúñiga V, Añaños F, Domènech E, Morillas RM, Gassull MA. Impact of periampullary duodenal diverticula at endoscopic retrograde cholangiopancreatography: a proposed classification of periampullary duodenal diverticula. Surg Laparosc Endosc Percutan Tech 2006;16:208-211.

4. Chen L, Xia L, Lu Y, Bie L, Gong B. Influence of periampullary diverticulum on the occurrence of pancreaticobiliary diseases and outcomes of endoscopic retrograde cholangiopancreatography. Eur J Gastroenterol Hepatol 2017;29:105-111

5. Güitrón-Cantú A, Adalid-Martínez R, Gutiérrez-Bermudez JA, Segura-López FK, García-Vázquez A. [Difficulty to cannulate papilla of Vater in the presence of periampullary duodenal diverticulum]. Rev Gastroenterol Mex 2010;75:273-280

6. Harada H, Suehiro S, Shimizu T, Katsuyama Y, Hayasaka K. Submucosal injection can facilitate biliary access in patients with periampullary diverticula. Gastrointest Endosc 2016;84:185-186.
7. Altonbary AY, Bahgat MH. Endoscopic retrograde cholangiopancreatography in periampullary diverticulum: the challenge of cannulation. World J Gastrointest Endosc 2016;8:282-287.

8. Parlak E, Köksal AS, Dişibeyaz S, et al. Additional biliary cannulation methods in patients with juxtapapillary duodenal diverticula. Dig Dis Sci 2012;57:2982-2987.

9. Cappell MS, Mogrovejo E, Manickam P, Batke M. Endoclips to facilitate cannulation and sphincterotomy during ERCP in a patient with an ampulla within a large duodenal diverticulum: case report and literature review. Dig Dis Sci 2015;60:168-173.

10. Fujita N, Noda Y, Kobayashi G, Kimura K, Yago A. ERCP for intradiverticular papilla: two-devices-in-one-channel method. Endoscopic retrograde cholangiopancreatography. Gastrointest Endosc 1998;48:517520.

11. Elmunzer BJ, Boetticher NC. Reverse guidewire anchoring of the papilla for difficult cannulation due to a periampullary diverticulum. Gastrointest Endosc 2015;82:957.

12. Külling D, Haskell E. Double endoscope method to access intradiverticular papilla. Gastrointest Endosc 2005;62:811-812.

13. Myung DS, Park CH, Koh HR, et al. Cap-assisted ERCP in patients with difficult cannulation due to periampullary diverticulum. Endoscopy 2014;46:352-355.

14. Wang BC, Shi WB, Zhang WJ, et al. Entering the duodenal diverticulum: a method for cannulation of the intradiverticular papilla. World J Gastroenterol 2012;18:7394-7396.

15. Kim HJ, Kim YS, Myung SJ, et al. A novel approach for cannulation to the ampulla within the diverticulum: double-catheter method. Endoscopy 1998;30:S103-S104.

16. Tóth E, Lindström E, Fork FT. An alternative approach to the inaccessible intradiverticular papilla. Endoscopy 1999;31:554-556.

17. Calvo MM, Bujanda L, Heras I, et al. The rendezvous technique for the treatment of choledocholithiasis. Gastrointest Endosc 2001;54:511-513.

18. Tarantino I, Barresi L, Fabbri C, Traina M. Endoscopic ultrasound guided biliary drainage. World J Gastrointest Endosc 2012;4:306-311.

19. Testoni PA, Mariani A, Aabakken L, et al. Papillary cannulation and sphincterotomy techniques at ERCP: European Society of Gastrointestinal Endoscopy (ESGE) clinical guideline. Endoscopy 2016;48:657-683.

20. García-Cano J. Use of an ultrathin gastroscope to locate a papilla hidden within a duodenal diverticulum. Endoscopy 2010;42 Suppl 2:E96-E97. 